\title{
O Enfermeiro e a prevenção das infecções do sítio cirúrgico
}

Nurses and prevention of surgical site infections of

1 Junia Pisaneschi Jardim Rocha junia.pisaneschi@gmail.com

2 Clarice Aparecida Simão Lages

1 Universidade Estácio de Sá.

2 Universidade Estácio de Sá

\section{Resumo}

As infecções hospitalares (IH) são definidas como aquelas adquiridas após, durante e até mesmo depois da internação do paciente, desde que possam ser relacionadas com a internação ou procedimentos invasivos. A multiplicidade de fatores que envolvem o controle de infecções tem dificultado a implementação de um efetivo programa de ações preventivas e controladoras, representando desafios cada vez maiores aos profissionais de saúde. Assim, foram objetivos do presente estudo de pesquisa bibliográfica descrever as principais causas de infecção no sítio cirúrgico; pesquisar a atuação da Comissão de Controle de Infecção Hospitalar $(\mathrm{CClH})$ na prevenção das Infecções no sítio cirúrgico e; investigar as condutas de Enfermagem para a prevenção das Infecções no sítio cirúrgico. Por fim, observou-se a importância do Programa de Controle de Infecções Hospitalares e da atuação do enfermeiro na prevenção das infecções hospitalares.

\section{Palavras-chave}

Infecções hospitalares; programa de controle de infecções hospitalares; enfermeiro.

\begin{abstract}
Hospital infections (HI) are defined as those acquired after, during and even after the patient admission, provided they are related to hospitalization or invasive procedures. The multiplicity of factors involving infection control has hindered the implementation of an effective program of preventive and controlling actions, representing increasing challenges to health professionals. So the objectives of this study were a literature research to describe the main causes of infection at the surgical site; also, to investigate the role of the Hospital Infection Control Commission $(\mathrm{CCIH})$ in the prevention of infections in surgical site, and to investigate the Nursing actions for the prevention of infections at the surgical site. Finally, the importance of the Nosocomial Infection Control Program and the work of nurses in the prevention of nosocomial infections was noted.
\end{abstract}

\section{Keywords}

Nosocomial infections; nosocomial infection control program; nurse.

\section{Como você deve citar?}

ROCHA, Junia Pisaneschi Jardim; LAGES, Clarice Aparecida Simão. O Enfermeiro e a prevenção das infecções do sítio cirúrgico. Cadernos UniFOA, Volta Redonda, n. 30, p. 117-128, abr. 2016. 


\section{INTRODUÇÃO}

Segundo Potter et al. (2013), a taxa de incidência de clientes que desenvolvem infecções como resultado direto de contato durante os cuidados de saúde está aumentando, fazendo com que a enfermagem, devido ao seu contato direto e recorrente com os clientes, tenha um papel primordial no controle de infecção. Os usuários dos estabelecimentos de saúde estão em risco de adquirir infecções, devido à baixa resistência orgânica e à maior exposição aos patógenos e aos procedimentos invasivos (POTTER et al., 2013).

A Infecção do Sítio Cirúrgico (ISC) é uma das principais IRAS no Brasil, ocupando a terceira posição entre todas as infecções ocorridas em serviços de saúde, compreendendo cerca de $14 \%$ a $16 \%$ daquelas encontradas em pacientes hospitalizados (ANVISA, 2009).

A Organização Mundial da Saúde (OMS), com base em dados recentes, considera que 1,4 milhão de infecções ocorre a qualquer momento, tanto em países desenvolvidos, quanto em desenvolvimento. Nos Estados Unidos da América (EUA), estimam-se que cerca de 2 milhões de infecções relacionadas à assistência em saúde ocorram anualmente, resultando entre 60 e 90 mil mortes, com um custo aproximado de, pelo menos, 17 a 29 bilhões de dólares. Em média, de 5\% a 15\% de todos os pacientes internados desenvolvem Infecções Relacionadas à Assistência à Saúde (IRAS) (WHO, 2009).

Segundo a Portaria n. 2616, de 1998 do Ministério da Saúde, Infecção Hospitalar (IH) é aquela adquirida após a admissão no nosocômio, cujas manifestações ocorrem a partir de 72 (setenta e duas) horas da admissão do paciente, ou após a alta, quando relacionada com a internação ou a procedimentos hospitalares/ambulatoriais.

A maioria das IHs manifesta-se como complicações de pacientes gravemente enfermos, em consequência da hospitalização e da realização de procedimentos, invasivos ou imunossupressores, a que o paciente foi submetido (PEREIRA et al., 2005).

Por muitos séculos, o homem, por falta de conhecimentos científicos a respeito da disseminação das moléstias, não eram isolados, convivendo lado a lado com pacientes terminais infectados, aumentando a ocorrência do alastramento das chamadas infecções (OLIVEIRA; CARVALHO, 2000). Somente no século XII, os pesquisadores começaram a demonstrar interesse nas chamadas IHs e no seu controle, através da cura, envolvendo a criação dos antibióticos (CARRARO, 2004). Pouco tempo depois, esses microrganismos causadores das IHs tornarem-se resistentes a muitos antibióticos, dentre eles: a penicilina, a meticilina, a flucoxacilina, entre outros (MERCIER, 1997).

Visto que as bactérias representavam um grande problema de Saúde Pública, em 1950, surgiram nos EUA as Comissões de Controle da Infecção Hospitalar (CCIHs), tornando-se obrigatórias em todos os hospitais do Brasil, em 1983, de acordo com a OMS, pela Portaria n 196/1983. Em 1992, divulgouse que, além da $\mathrm{CCIH}$, todos os hospitais do país deveriam implementar os Serviços de Controle da Infecção Hospitalar (SCIH) (CHIANCA et al., 2002).

Há quinze anos, em estudo realizado nos hospitais do Município de São Paulo (SP), em 2000 , constatou-se que nem todos os hospitais possuíam a CCIH. Os que implementaram a CCIH e o SCIH relataram dificuldades em dar continuidade ao programa, por falta de manutenção, verba e resistência em relação à mudança dos comportamentos dos funcionários (TURRINI, 2004). 
Conforme Gonçales e Fonseca (2004), 80\% das IHs são causadas pela flora normal do próprio paciente e $20 \%$ são transmitidas pelas mãos dos profissionais de saúde, contaminação dos artigos médico-hospitalares, equipamentos e ambiente. Para controlar essa disseminação é necessário educação permanente dos profissionais de enfermagem que, na maior parte do tempo, presta assistência direta ao paciente.

Segundo Bezerra (2002), a educação permanente é que vai melhorar o atendimento ao cliente, fazendo com que os profissionais se tornem cada vez mais capacitados a exercerem com qualidade as suas funções. É a educação que melhorará também os graus de risco do pessoal da enfermagem na contaminação hospitalar.

Sendo assim, os objetivos desta pesquisa são: descrever as principais causas de Infecção no Sítio Cirúrgico; pesquisar a atuação da CCIH na prevenção das Infecções no Sítio Cirúrgico e; investigar as condutas de Enfermagem para a prevenção das Infecções no Sítio Cirúrgico.

A problemática do estudo é relevante, uma vez que está relacionada ao fato de que a ISC, como todas as outras IRAS, é uma questão de saúde pública e apresenta um caráter, na maioria dos casos, prevenível. O sistema de saúde é constantemente desafiado por essas complicações infecciosas, aumentando assim a morbimortalidade entre os pacientes e elevando os custos hospitalares (SANTOS et al., 2005).

Esse estudo se justifica pelo fato de que a prevenção é o meio mais simples, mais barato e mais eficiente para lutar contra a infecção, em especial a ISC. Assim, anseia-se que a pesquisa possa contribuir para ampliar o conhecimento dos acadêmicos de enfermagem e dos enfermeiros em relação às medidas preventivas de ISC e para buscar estratégias para o alcance desta finalidade, o que possibilitará uma melhor assistência ao paciente cirúrgico.

\section{METODOLOGIA}

A presente pesquisa é bibliográfica integrativa. É descritiva, pois realizou-se o estudo, a análise, o registro e a interpretação da síntese de conhecimento e a incorporação da aplicabilidade de resultados de estudos significativos na prática sem a interferência do pesquisador, conforme aponta Gil (1996). A pesquisa é bibliográfica, pois procura explicar um problema a partir de referências teóricas publicadas em artigos, livros, dissertações e teses (CERVO; BERVIAN; SILVA; 2006).

Para aplicação da metodologia escolhida, inicialmente, foi realizada uma busca preliminar na biblioteca da Universidade Estácio de Sá e na internet por trabalhos científicos, monografias, dissertações e teses relacionadas ao tema estudado, utilizando as palavras-chave "Infecções Relacionadas à Assistência à Saúde", "Infecção Hospitalar", "Enfermagem", "Infecção de Sítio Cirúrgico", "Hospital Acquired Infections", "Nosocomial Infections" e "Surgical Site Infection". Foi feita também consulta às bases de dados do sistema Medline, Pubmed, Lilacs, Bireme e Scielo, com a finalidade de identificar os estudos com conteúdo mais adequado para contemplar os objetivos propostos.

A seleção da bibliografia e dos documentos que foram utilizados no estudo se iniciou em fevereiro de 2015 e utilizou, como principal critério de inclusão, a especificidade dos materiais em relação ao tema do estudo, sendo priorizado aqueles que incluíam dados oficiais e informações decorrentes de trabalhos científicos. 


\section{REVISÃo DE LITERATURA}

\subsection{Definição de Infecção Hospitalar}

A IH pode ser definida como qualquer infecção adquirida após admissão do paciente no hospital, podendo manifestar-se durante a internação ou após alta hospitalar. É também conhecida pela denominação: infecção propriamente dita, institucional ou nosocomial (BEN; MOURA, 1996).

Toda infecção constatada no momento da admissão do paciente em período de incubação será conceituada por infecção comunitária (IC). Já a infecção manifestada, a partir de 72 horas, após admissão, é conceituada pela IH (AZAMBUJA, 2004).

Moura e Tyrrel (2003) classificam a IH, desde que se manifeste durante o período de internação ou mesmo após alta hospitalar até 30 dias, relacionada com a internação ou procedimentos hospitalares.

Essa infecção instalada é definida com a invasão do hospedeiro por organismos vivos, tais como: bactérias, fungos, vírus, protozoários ou vermes, com ou sem doença (GONÇALES; FONSECA, 2004).

Conforme Souza et al. (1999), é classificada como infecção endógena (infecção associada à patologia de base ou agravos a microbiota do paciente) e infecção exógena (que é aquela que pode ser prevenida por estar relacionada aos procedimentos invasivos e aos cuidados com a lavagem das mãos).

Já a Infecção do Sítio Cirúrgico (ISC) pode ser definida como a infecção que ocorre na incisão cirúrgica ou em tecidos manipulados durante o procedimento cirúrgico, diagnosticada até 30 dias após o procedimento. Em caso de implante ou prótese, é a infecção que pode ocorrer até 1 ano após a cirurgia (OLIVEIRA; CARVALHO, 2000).

Conforme Ayliffe et al. (1998), a infecção é a instalação e a multiplicação de vários microrganismos nos tecidos de nosso organismo. Essa colonização se inicia com a ausência da ação do sistema imunitário do hospedeiro. Os autores definem que a IH é a infecção adquirida no hospital, na internação, ou pelos membros do staff (profissionais de saúde). A autoinfecção (endógena) é a infecção resultante da própria microbiota do paciente (microrganismos residentes e transitórios).

Segundo Bolick et al. (2000), esses microrganismos instalados provocam lesões decorrentes da competição direta com o organismo endógeno ou através da liberação de toxinas produzidas. Esse sistema de defesa do paciente, muitas vezes, poderá agravar essa lesão localizada ou sistêmica. 0 paciente hospitalizado encontra-se exposto a uma variedade de microrganismos, sendo que a instalação dessas bactérias ocorre num determinado momento em que o organismo não consegue combatê-las, já que o paciente já se encontra sobre estresse resultante de sua patologia e internação. Dessa forma, o mecanismo de defesa já está debilitado, principalmente se a pessoa já passou por processo cirúrgico, fora os tratamentos farmacológicos e procedimentos invasivos do tratamento, que comprometem a integridade da pele, sendo porta de entrada da infecção.

Existem critérios para classificar uma IH. São eles: ausência de infecção e fora do período de incubação na admissão, quando a infecção adquirida no hospital se torna evidente na alta hospitalar; no recém-nascido (Rn), quando a infecção é adquirida no cordão umbilical. Em caso de nova suspeita de infecção no mesmo paciente é classificada quando o surgimento da infecção ocorre em outro local diferente com o mesmo microrganismo, isolamento de microrganismos diferentes. 
Não são consideradas IHs os casos de complicações de infecção presentes na admissão, a não ser o instalação de novo patógeno, infecção por via transplacentária (herpes, toxoplasmose, rubéola, cetamegalovírus e sífilis, que se manifestam até 48 horas) (MARTINS et al., 1993).

A IH é evidenciada por meio da observação direta do paciente (exame físico), informações do prontuário e da unidade de enfermagem (relatórios), exames laboratoriais e imagenocológicos e diagnóstico clínico (MARTINS et al., 1993).

Segundo Couto e Nogueira (1997), o tempo para definição de IH, será de, no máximo, até 48 horas para pós-alta da unidade de terapia intensiva (UTI); 30 dias, após cirurgia com ausência de prótese; 1 ano, após cirurgia com presença de prótese e qualquer infecção no neonato, até 28 dias de vida, desde que esteja ausente infecção adquirida por via-transplacentária.

\subsection{Fontes e Fatores de Risco da Infecção Hospitalar}

As fontes da IH são definidas como o local que os microrganismos patogênicos evoluem até seu crescimento e por onde são transmitidos para o hospedeiro susceptível, considerando que o reservatório é o local onde esses microrganismos causadores de potenciais doenças conseguem sobreviver fora do organismo e o meio pelo qual são transferidos direta ou indiretamente para o indivíduo. Os veículos serão os carreadores dessas bactérias, denominado também de vetores (AYLIFFE et al., 1998).

As pessoas doentes e aquelas com baixa imunidade encontram-se situadas em um mesmo local, sendo fontes de infecção para si própria, para os outros pacientes e para o próprio ambiente, de forma a transmitir pelo contato físico direto, pelas mãos, pelo contato indireto, por objetos contaminados e pelo ar (CHIANCA et al., 2002).

Em pesquisas, constatou-se que o mecanismo de transmissão é a maneira como os agentes saem da porta de saída do reservatório para o hospedeiro susceptível dos seis elos da cadeia infecciosa. A infecção pode ser transmitida por quatro mecanismos, sendo eles: o contato, o ar, o veículo e o vetor.

Já alguns microrganismos usam vários mecanismos de transmissão, como por exemplo: os vírus da catapora e do sarampo, que são transmitidos por contato; a tuberculose (Tb), pelo ar; a cólera, por um veículo e; a doença de Chagas, por um vetor. A transmissão por contato ocorre por subdivisão: direta, indireta ou por disseminação (através de perdigotos).

Muitas instituições prestam serviços, investigando a maneira de transmissão da infecção: a transmissão por contato direto é a disseminação dos microrganismos de um indivíduo para o outro, através do contato físico real e também por micróbios, que são transmitidos diretamente pela transferência de atividades de assistência ao paciente, tais como: banho, troca de curativos, introdução de dispositivos invasivos, sem contar com as mãos de profissionais de saúde e suas luvas contaminadas.

Assim outras doenças se espalham por contato direto, como a Escabiose, Herpes simples e, se houver contato direto, com lesões orais ou com secreções infectadas.

Outro meio de transmissão é o contato indireto, onde o indivíduo susceptível entra em contato com o objeto contaminado. As instituições prestadoras de serviços de saúde relatam que quase todos os objetos, como o termômetro, seringas, endoscópio, soluções usadas para irrigação, catéteres urinários e intravasculares (IV), equipamentos respiratórios, fraldas e brinquedos são contaminados pela ineficácia asséptica. Logo, a transmissão por perdigotos resulta no contato com secreções respi- 
ratórias contaminadas, uma vez que o indivíduo infectado tosse, espirra na conversa e libera secreções infectadas, que se espalham pelo ar e chegam às mucosas orais e nasais de outra pessoa próxima.

Os micróbios presentes nas gotículas do muco podem ser transportados por até um metro. Essas transmissões não permanecem suspensas no ar, pois se depositam na superfície, disseminando a influenza, a pneumonia e a coqueluche, entre outras.

Na transmissão do ar, as partículas microbianas minúsculas, contidas na poeira com agentes patogênicos permanecem suspensas no ar por um período prolongado e, em seguida, são disseminadas amplamente pela corrente de ar e inaladas. Tais partículas microscópicas permanecem suspensas ao ar por várias horas, podendo causar infecção, quando um indivíduo susceptível inalar essas partículas e o bacilo da Tb chegar aos pulmões. Assim, a transmissão por veículo, até que o mesmo seja ingerido ou inoculado em um hospedeiro susceptível, não é classificada como perigo, mas pode transportar micróbios patogênicos por meio de água, sangue, soro, plasma, fármacos, alimentos e vegetais mal lavados e fezes, promovendo a infecção. Porém, essa transmissão costuma ocorrer na comunidade, mas não é comum em hospitais. A transmissão por vetor ocorre por um portador intermediário (pulga ou mosquito), transferindo doenças para outro ser vivo. A porta de entrada é o quinto elo da cadeia de transmissão de uma infecção e o caminho por meio da qual um agente infeccioso invade o hospedeiro susceptível (BOLICK et al., 2000).

Para que a infecção se instale dependerá apenas da imunidade do paciente, que geralmente se encontra baixa, quando o organismo não consegue se defender desses patógenos. Já o ambiente onde o paciente se localiza para seu tratamento pode influenciar muito na sua forma de contrair a infecção, pois, em cada área hospitalar, a infecção se predispõe em uma forma específica. 0 tratamento também tem grande importância na proliferação dos microrganismos, pois o uso de drogas imunossupressoras ou esteroides faz com que haja diminuição na sua imunidade celular (AYLIFFE et al., 1998).

Conforme Bem e Moura (1996), os microrganismos que habitam na pele e mucosas (tratos digestivos, respiratórios ou geniturinários) são as principais causas das IHs, em conjunto com a baixa resistência do paciente, manuseio de artigos médico-hospitalares mal esterilizados e uma equipe de assistência desqualificada.

Existem vários fatores que contribuem para disseminação da infecção, entre eles: fatores relacionados ao agente etiológico, ao ambiente e aos fatores do hospedeiro (paciente), como idade avançada; imunocomprometimento (Síndrome da Imunodeficiência Adquirida - SIDA/HIV); morbidades; procedimentos invasivos, como intervenções cirúrgicas, ventilação mecânica assistida, implantação de corpos estranhos no organismo, uso inadequado de medicamentos e antimicrobianos; baixo nível de educação e outros (CHIANCA et al., 2002).

De acordo com Santos (2004), a saúde da população encontra-se ameaçada pelas bactérias que, cada vez mais, se tornam resistentes aos antibióticos usados de maneira inadequada, em grandes quantidades, principalmente dentro dos hospitais.

Um terço das bactérias Staphilococcus aureus é encontrada em pele e no nariz, provocando diversas infecções médias (manchas, bolhas e abscessos) e infecções mais sérias (pneumonia e septicemia), com capacidade de transmitir muito facilmente de uma pessoa para a outra (MERCIER, 1997).

Existem fatores de risco específicos para infecção em pacientes cirúrgicos que estão expostos: duração e extensão da cirurgia e anestesia, estresse, trauma anestésico-cirúrgico, período de hospitalização, paramentação cirúrgica, antissepsia, procedimentos técnicos empregados; as condições individuais do paciente (condições clínicas, patológicas, idade, terapêutica imunossupressora, estado nutricional, 
resposta inadequada de defesa); os materiais hospitalares (grande potencial de risco de transmissão de infecção, dependendo do material utilizado, limpeza, preparo, acondicionamento e esterilização dos materiais hospitalares) e ao ambiente (limpeza das salas de operações) (CHIANCA et al., 2002).

A pele atua como barreira de proteção para o organismo, entretanto uma ferida quebra esse equilíbrio, dependendo se a carga de bactéria é muito alta, se a defesa do hospedeiro está comprometida pela desnutrição, se há presença de doenças crônico-degenerativas, terapia imunossupressora, entre outras. 0 risco de contrair infecção aumenta com o grau de gravidade de sua patologia de base. A presença de uma doença maligna é um fator altamente associado à infecção cirúrgica. A obesidade, retorno venoso insuficiente, área isquêmica na ferida cirúrgica, deficiência no processo de cicatrização são apontados como fatores predisponentes à ISC. Quanto mais expostos, maior densidade das bactérias depositarem nos tecidos (CHIANCA et al., 2002).

Num estudo crítico sobre as IHs, nas áreas críticas do Hospital Getúlio Vargas (HGV), em Teresina, no contexto do processo do cuidar-cuidado de enfermagem, foi identificada a política institucional e funcional do HGV, que presta assistência a todo o estado do Piauí e estados vizinhos, sendo o hospital referência da capital de Teresina. São 1797 funcionários distribuídos de maneira irregular, com 180 profissionais de enfermagem (111 enfermeiros e 69 técnicos e auxiliares de enfermagem). Esse déficit de pessoal de enfermagem é um fator de risco para IH e de medidas de prevenção e controle. O percentual de pessoas circulantes no hospital cai para $90 \%$, resultando na má prática profissional. Essas áreas críticas oferecem risco potencial para o surgimento de qualquer infecção, seja por procedimentos invasivos ou por clientes susceptíveis às infecções, com falta de determinações político-administrativas para o cumprimento da Portaria do MS. Outro fator de risco envolve o processo de cuidar/cuidado: momentos de atenção ao pacientes internados, atitudes de ocupação, responsabilidade e envolvimento com o outro, além do seguimento de rotinas/normas e procedimentos próprios. Considerando os depoimentos com maior expressividade, a dimensão da competência, habilidade técnica, cumprimentos de rotinas dos serviços, as necessidades diagnósticas e conforto ao cliente e, com menor expressividade, a dimensão afetiva que envolve preocupação com dinâmica do serviço e com o cliente, necessidades básicas, sensibilidade e humanidade, reconhecendo a dificuldade dos profissionais de enfermagem em expor seus sentimentos e aspectos sociais em relação ao paciente, com influência do positivismo na valorização das técnicas pelas escolas de enfermagem (MOURA; TYRREL, 2003).

De acordo com Pereira e Bellato (2004), as condições do espaço físico, dos materiais e dos equipamentos nas instituições de saúde, são fatores, muitas vezes, deixados de lado na ocorrência da IH. Apesar das normas decretadas pelo MS, sabemos que, na realidade,o cumprimento delas não é concreto. Em contrapartida, sabe-se do risco de agravar o estado de saúde do cliente e o risco que os trabalhadores estão expostos a exercerem suas funções em condições inapropriadas, embasados no direito à saúde a todo o ser humano. O hospital é denominado como o território com muitas segmentações impostas, sendo o local de trabalho para o profissional de saúde e a busca de cura para o cliente hospitalizado. Desde o século XIX, a enfermeira Florence Nightingale, já havia apontado como deveria ser organizado o ambiente hospitalar, contribuindo para a melhora da saúde das pessoas internadas, entretanto, até hoje, vivenciamos a precarização do espaço físico e de equipamentos.

Foi realizado um estudo na instituição hospitalar de ensino de porte médio, do município de Cuiabá - Mato Grosso (MT), onde foi constatado precarizações, entre elas: falta de arejamento e de iluminação natural (números insuficientes de janelas e espaço físico disponível ao número de leitos); área $50 \%$ menor que o mínimo exigido por lei; número de leitos até $50 \%$ maior que o permitido para um hospital de médio porte. Foi verificado também que havia dois sanitários e um chuveiro para seis leitos de cada uma das enfermarias (sendo o ideal, conforme MS, um sanitário por leito e um chuveiro para cada dois leitos); uma pia para uso de todos os usuários das enfermarias, o que representa um importante vetor de contaminação. 
Foi também observado, tetos, pisos e paredes inadequadas, conforme a norma imposta, sendo um ambiente propício para a proliferação de microrganismos e fungos. 0 uso de ventiladores em enfermarias e locais de preparo de medicação, com aumento de movimentação de partículas de microrganismos, o que possibilita um ambiente potencialmente contaminado. Outro fator evidenciado deve-se ao calor excessivo durante o período noturno. 0 cliente se torna mais irritado, resultando um repouso prejudicado, sendo mais susceptível a infecções, devido à baixa resistência desencadeada pelo estresse físico (PEREIRA; BELLATO, 2004).

Os aparelhos de ar condicionado não são encontrados nas enfermarias, são encontrados na clínica médica e pediatria e em todas as áreas destinadas à equipe de saúde (salas de repouso, salas de aula e administrativa). A iluminação artificial está presente em todas as enfermarias e ausente em todas as clínicas, nas cabeceiras dos clientes. A higiene e limpeza dos pisos e paredes são realizadas, conforme rotina da própria instituição (produtos de limpeza e desinfecção utilizados seguem a norma legal) (PEREIRA; BELLATO, 2004).

Em contrapartida, a técnica de execução é inadequada, não respeitando os preceitos da limpeza, primeiramente, no local menos contaminado e, posteriormente, para o mais contaminado. Outra problemática é que a limpeza da instituição é realizada por firma terceirizada. A maior parte dos trabalhadores possui um baixo nível de escolaridade e a supervisão, geralmente, é feita por um funcionário que não detém conhecimentos sobre limpeza e desinfecção da área hospitalar (PEREIRA; BELLATO, 2004).

Nas enfermarias, as lixeiras não possuem tampas, sendo depositados nelas, materiais empregados em curativos, além de alimentos associados ao aumento da temperatura, elevando a possibilidade da decomposição de detritos orgânicos. As tampas devem ser herméticas acionadas por pedais, para se evitar possível contaminação das mãos e ambiente. A solicitação de troca foram feitas pelos enfermeiros, entretanto não foram atendidas. (PEREIRA; BELLATO, 2004).

Em relação às condições dos equipamentos e materiais, as camas e os colchões que estão presentes em número de leitos de cada clínica, apresentam-se danificadas e com áreas de corrosão, pelo longo tempo de uso e pela ação dos agentes químicos, expondo a pessoa internada a um maior risco de adquirir uma $\mathrm{IH}$, além dos problemas de funcionamento. Os suportes de soro apresentamse em número insuficiente em todas as clínicas, sendo antigos e com seu mecanismo de elevação enferrujado, restringindo ainda mais o cliente no leito e aumentando o risco de infecção. Os hampers estão disponíveis em números suficientes nas clínicas, mas com precárias condições de uso, rodinhas emperradas ou mesmo inexistentes, obrigando os trabalhadores a transportarem os sacos de roupas sujas/contaminadas com sangue e secreções, em contato com próprio corpo (PEREIRA; BELLATO, 2004).

Os carrinhos de curativos estão presentes em todas as clínicas, apresentando problemas de rodízios, com dificuldade de movimentação, além de danos das superfícies. Utilizam-se bandejas que são depositadas sobre o leito dos pacientes para realização do procedimento, uma vez que não há mesas auxiliares (PEREIRA; BELLATO, 2004).

Num estudo realizado sobre a percepção de odores e infecção em ambiente hospitalar, pela equipe de enfermagem, nas Clínicas de Internação Cirúrgica de um Hospital Universitário da cidade de Santa Catarina (SC), foi evidenciado que, de 5.303 observações complementares de enfermagem, 2.557 eram relativas a fenômenos odorantes e apenas 91 demonstraram relação com secreções corporais. A negação, a ocultação ou silêncio olfativo pela equipe demonstrou impedimento para evidência de riscos de infecções. Os odores hospitalares são deixados de lado por inúmeras instituições, tendo múltiplos significados, como a presença de um agente biológico relacionado a condições de risco de $\mathrm{IH}$ ou precariedade de higiene ambiental. Esses odores agradáveis ou desagradáveis permitem uma reação da equipe frente 
ao problema, sendo um perigo presente no ambiente, causa ou resultado de algum dano ou desconforto ao indivíduo, muitas vezes negligenciado por parte da equipe de enfermagem (WOSNY; ERDMANN, 2004).

Os profissionais de saúde contribuem em grande parte para a proliferação dos microrganismos e para sua própria contaminação, pois não utilizam as técnicas assépticas e sépticas adequadamente, como deveriam. A IH, atualmente, vem preocupando os estudiosos, em relação a sua alta taxa de mortalidade e morbidade mundial, pois ainda não encontrou uma resolução completa para esse problema. Santos (2004) ainda relata que quanto mais extenso o hospital, maior probabilidade de risco de multiplicação das bactérias, pois existirá uma maior transação de pessoas. Com isso, maior quantidade de procedimentos em pacientes serão executados, tendo uma maior propensão à proliferação de bactérias (SANTOS, 2004).

De acordo com Gonçales e Fonseca (2004), a IH depende da existência de uma fonte de infecção, das formas de transmissão, do agente etiológico e da suscetibilidade do cliente e de uma associação de vários fatores; sendo um ciclo vicioso, somente através da prevenção estaremos cessando a continuidade deste ciclo.

\subsection{O Papel da Enfermagem no Controle da Infecção Hospitalar}

Conforme Farias (1997), o treinamento é considerado o programa responsável pelo processo educacional, com o objetivo de adaptar o funcionário a exercer sua função. Já o aperfeiçoamento são programas ou atividades que visam à atualização desses profissionais.

Segundo Bezerra (1997), o GEECEN, Grupo de Estudos de Educação Continuada em Enfermagem, fundado no ano de 1991, com propósito de se responsabilizar pelo desenvolvimento técnico científico dos enfermeiros que atuam nessa área, a educação permanente é a melhor forma de manter os profissionais da área de saúde sempre atualizados e capacitados para executarem as suas funções. 0 enfermeiro tem um papel muito importante nessa área, pois estará repassando conhecimentos científicos aprendidos a sua equipe. Entretanto, para que desempenhe com competência o seu trabaIho, é necessário, primeiramente, que seja um enfermeiro atualizado, capacitado, que tenha uma boa formação acadêmica, possua experiências práticas, desenvolva comportamento estratégico, que tenha uma visão da cultura organizacional, habilidades para desenvolver atividades educativas, atualização contínua de conhecimentos, espírito de equipe, liderança, flexibilidade, autogerenciamento, conduta ética e que seja também comunicativo, pois necessitará da ajuda dos outros enfermeiros para darem continuidade ao seu trabalho educativo.

Conforme Bezerra (2002), é pela educação permanente que se alcançará a qualidade do atendimento ao cliente, fazendo com que os profissionais se tornem cada vez mais capacitados a estarem exercendo bem suas funções, bem como em prol da melhoria da saúde do trabalhador na área da saúde.

$\mathrm{O}$ conceito controle da IH refere-se à eliminação de fontes e a não disseminação das infecções no âmbito hospitalar (CHIANCA et al., 2002).

A lavagem das mãos é um procedimento importante na redução de infecções nosocomiais, sendo seu objetivo a remoção de todos os microrganismos não residentes, antes que possa ocorrer uma transferência para um doente suscetível, de fundamental importância ao lidarmos com os dispositivos invasivos, tais como, os cateteres IV, prevenindo um potencial de infecção. Estudos demonstraram que esse procedimento é muito negligenciado por parte dos profissionais de saúde, incluindo a enfermagem, apesar de ter um importante papel na redução das infecções. Quando lidamos com os dispositivos invasivos, ultrapassamos as barreiras naturais do corpo contra as bactérias, aumentando o risco de infecção adquirida no hospital (VOST, 1998). 
O enfermeiro deverá desenvolver atividades de educação sanitária, visando tanto à saúde individual quanto à coletiva. Além da lavagem rigorosa das mãos, é necessário que os profissionais, ao assistirem os clientes, devem ter em mente a remoção de objetos do uso pessoal (anéis, pulseiras, relógios), pois esses objetos contêm microrganismos que podem ser transmitidos de uma pessoa a outra, acarretando infecções.

\section{COMENTÁRIOS}

Os estudos apontaram que a IH pode ocorrer após admissão do paciente, durante a sua permanência no hospital, podendo ser evidenciada também na pós-alta hospitalar, lembrando que não são classificadas como Ihs, a IC identificada no momento da admissão do paciente no hospital e a infecção adquirida por via transplacentária.

A IH representa a principal causa de morbidade, mortalidade e aumento nos gastos assistenciais nas instituições de saúde. Devido à consequência desse problema, tornou-se obrigatório à implementação da CCIH e SCIH. Nos EUA, no ano de 1950, e, no Brasil, no ano de 1983 (CHIANCA et al., 2002).

Em contrapartida, muitos hospitais encontram dificuldade em incrementar o programa devido à resistência à mudança de hábitos entre os profissionais de saúde e a precarização de muitas instituições hospitalares.

A IH torna-se mais susceptível em pacientes imunodeprimidos que devido à sua patologia de base, se submetem a diversos tipos de procedimentos como: invasivos, processos cirúrgicos e terapêuticas farmacológicas, porta de entrada para os microrganismos patógenos.

A transmissão da IH se dá em decorrência do contato direto ou indireto, do ar, do veículo e do vetor (BOLICK et al., 2000).

Essa infecção dependerá da existência de uma fonte, das formas de transmissão citadas acima, do agente etiológico e da susceptibilidade do cliente e de uma associação de vários fatores, sendo um ciclo vicioso (GONÇALES; FONSECA, 2004).

As principais infecções adquiridas no hospital são a pneumonia hospitalar, a bacteremia associada a úlceras de pressão infectadas, infecção do trato urinário, relacionada à inserção de cateterismo vesical. Essas infecções não tratadas poderão evoluir para uma septicemia, levando a um quadro clínico grave, podendo levar o paciente à morte (CARPENTER et al., 1998).

Para se combater a IH é necessária, primeiramente, a capacitação da equipe de saúde, através da educação permanente, assim como da instituição, utilizando medidas preventivas por meio da implementação e seguimento de programas da $\mathrm{CCIH}$ e SCIH, como assepsia e antissepsia corretas,com ênfase primordial à lavagem das mãos, que, embora seja uma técnica tão simples, não é utilizada com frequência por muitos dos profissionais de saúde, sendo o principal vetor para a disseminação da infecção.

\section{CONSIDERAÇÕES FINAIS}

Através deste levantamento bibliográfico pode-se observar o quanto as infecções hospitalares ainda são discutidas e temidas por estudiosos e profissionais da saúde, acerca de suas consequências no âmbito hospitalar, principalmente em Unidades de Terapia Intensiva. 
$\mathrm{O}$ controle de IH está diretamente relacionado à mudança de comportamento dos profissionais de saúde que devem estar convencidos da importância dessa mudança. Assim, através de estudos, o método de lavagem das mãos ainda é considerado o meio mais simples e eficiente para o controle das infecções, porém a falta de informações científicas sobre o impacto definitivo da melhoria da higiene das mãos nas taxas de infecções associadas aos cuidados com a saúde é uma possível barreira à adesão apropriada, às recomendações para higiene das mãos.

É necessário que todos os profissionais da área da saúde que estão envolvidos diretamente com a assistência a saúde tenham consciência que o $\mathrm{ClH}$ é fundamental para o processo de cuidar.

Portanto, conclui-se que o Programa de Controle de Infecção Hospitalar merece destaque para o auxílio na divulgação e implementação de medidas preventivas das infecções, facilitando o serviço do enfermeiro para com sua equipe e, consequentemente, aperfeiçoando a qualidade da assistência prestada.

\section{REFERÊNCIAS}

ANVISA. Sítio Cirúrgico: Critérios Nacionais de Infecções relacionadas à assistência à saúde. Brasília, 2009. Disponível em: <http://www.anvisa.gov.br/servicosaude/manuais/criterios_nacionais_ISC.pdf>. Acesso em: 08 de mar. 2015.

AYLIFFE, G.A.J et al. Controle de infecção hospitalar. manual prático. Rio de Janeiro: Revinter, 1998, p. 1-8.

AZAMBUJA, E.P.D et al. Prevenção e Controle da Infecção Hospitalar. As Interfaces com o Processo de Formação do Trabalhador. Rev. Texto e Contexto Enferm. v.13, nesp, p.79-86, 2004.

BEN, L.W.D.B; MOURA, M.L.P.A. Prevenção e controle de infecção hospitalar para enfermeiros. São Paulo: Senac, 1996, p.9-15.

BEZERRA, A.L.Q. 0 contexto da educação continuada em enfermagem na visão de gerentes de enfermagem e dos enfermeiros de educação continuada. Rev. Paulista de Enfermagem. v.21, n³, p.288-289, 2002.

BEZERRA, A.L.Q. Perfil do Enfermeiro de Educação Continuada. Rev. Paulista de Enfermagem, v.16, n $1 / 3$, p.72-82, 1997.

BOLICK, D et al. Segurança e controle de infecção. Rio de Janeiro: Reichmann \& Affonso editores, 2000, p.79-123.

CARPENTER, C.C.J et al. Infecções Hospitalares.In: ANDREOLI, T.E et al. Cecil Medicina Interna Básica. Rio de Janeiro: Guanabara, 1998, p.707-709.

CARRARO, T.E. Os Postulados De Nightingale E Semmelweis: Poder/Vital E Prevenção/Contágio Como Estratégias Para A Evitabilidade Das Infecções. Rev. Latino-am Enfermagem, v. 12, n4, p.650-657, 2004.

CERVO, A. L.; BERVIAN, P. A.; SILVA, R. Metodologia científica. São Paulo: Person Education, 2006.

CHIANCA, T.C.M et al. As Comissões de Infecção Hospitalar e as Unidades de Centro Cirúrgico: Uma Reflexão Histórico-Crítica acerca da Prática. Rev. Técnica de Enfermagem-Nursing, v.5, n46, p.22-28, 2002.

COUTO, R.C; NOGUEIRA, J.M. Critérios Diagnósticos das Infecções Hospitalares. In: COUTO, R.C et al. Infecção Hospitalar: Epidemiologia e Controle. Rio de Janeiro: MEDSI, 1997, p.39. 
FARIAS, A.C.M. Atualidades E Perspectivas Em Educação Continuada: Treinamento E Aperfeiçoamento De Pessoal. Rev. Paulista de Enfermagem. v.6, n¹/3, p.64-66, 1997.

GIL, Antonio Carlos. Como elaborar projetos de pesquisa. 3. ed. São Paulo: Atlas 1996.

GONÇALES, M.B; FONSECA, A.D.S. Visão dos Docentes de Enfermagem quanto aos Cuidados Básico para Prevenção de Infecção. Rev. Técnica de Enfermagem-Nursing, v.78, nº, p.23-28, 2004.

MARTINS, M.A et al. Manual de infecções hospitalares: prevenção e controle. São Paulo: MEDSI, 1993, p.1-5.

MERCIER, C. Parar o supermicróbio. Rev. Técnica de Enfermagem-Nursing, v.10, n¹16, p.9-10, 1997.

MOURA, M.E.B; TYRREL, M.A.R. A Infeç̧ão Hospitalar no Piauí: a crítica e os aspectos críticos no processo de cuidar-cuidado em enfermagem. Rev. Técnica de Enfermagem-Nursing, v.6, n66, p.31-36, 2003.

OLIVEIRA, A.C; CARVALHO, D.V. Infecções de Sítio Cirúrgico Pós-Alta Hospitalar. Rev. Técnica de Enfermagem-Nursing, v.3, n³1, p.17-21, 2000.

PEREIRA, W.R; BELLATO, R. A Relação Entre A Precarização Do Ambiente Físico E O Risco De Infecção Hospitalar. Um Olhar Sob A Perspectiva Da Ética, Dos Direitos E Da Cidadania. Rev. Texto e Contexto Enferm. v.13, nesp, p.17-24, 2004.

PEREIRA, M.S. et al. A infecção hospitalar e suas implicações para o cuidar da enfermagem. Revista Texto Contexto Enfermagem. Abr-Jun. 2005 p. 250-257 Disponível em:<http://www.scielo.br/scielo. php?pid=S0104-07072005000200013\&script=sci_arttext> Acesso em: 07 de mar. 2015.

POTTER, Patrícia A. et al. Fundamentos de Enfermagem. 8. ed. Rio de Janeiro: Elsevier, 2013.

SANTOS, A.A.M. et al. Diagnóstico do controle da infecção hospitalar no Brasil. Programa de pesquisas hospitalares em busca de excelência: fortalecendo o desempenho hospitalar no Brasil. Brasília: Agência Nacional de Vigilância Sanitária/Banco Mundial, 2005.

SANTOS, N.D.Q. A Resistência Bacteriana no Contexto da Infecção Hospitalar. Rev. Texto e Contexto Enferm. v.13, nesp, p.64-70, 2004.

SOUZA, N.V.D.O et al. Gente que Cuida de Gente com Infecção Hospitalar. Rev. Técnica de EnfermagemNursing, v.2, $n^{\circ} 14$, p.15-19, 1999.

TURRINI, R.N.T. Programa de Controle de Infecção Hospitalar. problemas na implantação em hospitais do Município de São Paulo. Rev. ACTA Paul. Enf. v.17, n³, p.316-323, 2004.

VOST, J. Controle da Infecção Hospitalar e Questões Relacionadas na Terapêutica Intravenosa. Rev. Técnica de Enfermagem-Nursing, v.1, n5, p.29-34, 1998.

WORLD HEALTH ORGANIZATION. Guidelines on Hand Hygiene in Health Care. First Global Patient Safety Challenge Clean Care is Safer Care. World Health Organizations; 2009. Disponível em: <http://apps.who. int/iris/bitstream/10665/44102/1/9789241597906_eng.pdf>. Acesso em: 21 set. 2015.

WOSNY, A.D.M; ERDMANN, A.L. Odores E Infecções Em Ambiente Hospitalar. A Negação Do Óbvio No Registro Das Observações Da Enfermagem. Rev. Texto e Contexto Enferm, v.13, nesp, p.58-63, 2004. 